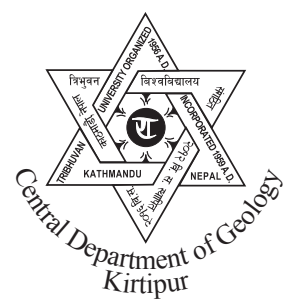

\title{
Rock Mass Rating and Geological Strength Index of rock masses of Thopal-Malekhu River areas, Central Nepal Lesser Himalaya
}

\author{
Jaya Laxmi Singh and *Naresh Kazi Tamrakar \\ Central Department of Geology, Tribhuvan University, Kathmandu, Nepal
}

\begin{abstract}
The rock slopes of the Thopal-Malekhu River areas, Lesser Himalaya, were characterized applying various systems of rock mass classification, such as Rock mass Rating (RMR) and Geological Strength Index (GSI), because the study area comprises well exposed rock formations of the Nawakot and Kathmandu Complexes, across the Thopal-Malekhu River areas. In RMR system, mainly five parameters viz. Uniaxial Compressive Strength (UCS) of rock, Rock Quality Designation (RQD), spacing of discontinuity, condition of discontinuity, and groundwater condition were considered. The new GSI charts, which were suitable for schistose and much disintegrated rock masses, were used to characterize rock slopes based on quantitative analysis of the rock mass structure and surface condition of discontinuities. RMR ranged from 36 to 82 (poor to very good rock mass) and GSI from $13.5 \pm 3$ to $58 \pm 3$ (poor to good rock mass). Slates (of the Benighat Slate) are poor rock masses with low strength, very poor RQD, and close to very close spacing of discontinuity, and dolomites (Dhading Dolomite) are fair rocks with disintegrated, poorly interlocked, and heavily broken rock masses yielding very low RMR and GSI values. Phyllites (Dandagaun Phyllite), schist (Robang Formation) and quartzite (Fagfog Quartzite, Robang Formation and Chisapani Quartzite), dolomite (Malekhu Limestone), and metasandstone (Tistung Formation) are fair rock masses with moderate GSI and RMR values, whereas quartzose schist and gneiss (Kulekhani Formation) are very good rock masses having comparatively higher RMR and GSI. The relationship between GSI and RMR shows positive and good degree of correlation.
\end{abstract}

Key words: Rock mass characterization, Rock Mass Rating, Geological Strength Index, Malekhu River, Central Nepal Lesser Himalaya

\section{INTRODUCTION}

In mountain terrains of the Himalaya, road and highway networks play a vital role in transportation in remote areas, public networking and enhancing socioeconomic welfare. The Lesser Himalayan region is tectonically active zone that is characterized by a very complex structure of thrust sheets (Kumar, 1971). The character of the rock mass along the roads and highways

\footnotetext{
*Corresponding author:

E-mail address: ntamrakar@hotmail.com
}

is a major concern in these hilly regions. Any kind of slope failure along the way may lead to disruption in traffic, loss of properties and lives as well as environmental degradation. The unplanned excavations of rock slopes for construction or widening purposes may undermine the stability of the slopes.

Slope instability, rock mass and groundwater conditions and, critical zones as shear zones are anticipated engineering geological problems (Bhatta, 2006) that appear during the excavation. Therefore, the possible treatments recommended are largely based on the rock 
mass classification with the measurable parameters (Goodman, 1989). Roads are often found to extend along the hill slopes of the river course, which is prone to be disturbed by landslide and river erosion. The river corridors are frequently subjected to river bank erosion, slope movements and flash flooding (Shrestha and Tamrakar, 2007a; Shrestha et al. 2008; Tamrakar et al. 2011). Therefore, river bank slopes are required to be characterized for their condition. Also analyzing the past experiences of Nepal, thousands of lives and properties are being lost every year due to natural disaster (Upreti and Dhital, 1996). Therefore, mitigation measure is necessary applying engineering approach. Knowing the characteristic features and quality of rock mass, we can minimize such hazards caused by natural disasters.

Extension of highways and roads are associated with establishment of number of large engineering structures of which important ones being tunnels and bridges. Large volume of rock are involved in the design and construction of structure and excavation in rock such as dams, tunnels, underground power plants, embankments, trailing piles road cuts and open pit mines. The behavior of rock masses is governed by intact rock material properties and discontinuities (Sen and Sadagah, 2003). Strength of rock masses imparted to a large degree by shear strengths of discontinuity surfaces are typically dependent on one or more factors such as orientation, spacing, continuity, surface characteristics, the separation of discontinuity surface, and the accompanying thickness and nature of filling material (if present). There are several approaches that characterize and classify such large volume of rock which is known as geomechanical classification. Such as Rock Mass Rating (RMR) given by Bieniawski (1989) which is based on detailed field and laboratory study which involves collection of data at site slopes. Another approach is Geological Strength Index (GSI) after Hoek and Brown (1997) and Hoek et al., (1998), which provides a system for estimating the reduction in rock mass strength for different geological condition which is modified by Sonmez and Ulusay (1999) for disintegrated to Blocky rock mass and by Osgoui et al. (2010) for very poor rock mass. Values of GSI are related to both the degree of fracturing and condition of fracture surface. Therefore, both RMR and GSI approaches were utilized in the present study which is focused concerning the rock mass characteristics of road cut slope, and the Thopal and the Malekhu Riverbank slopes.

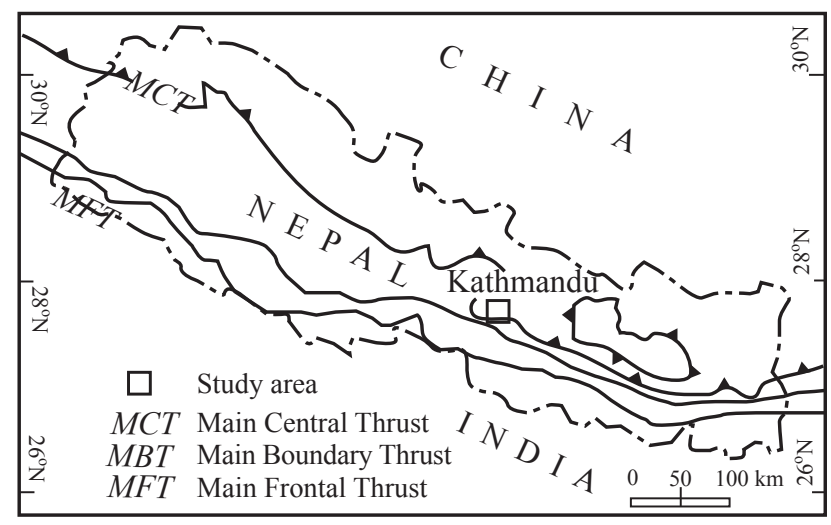

Fig. 1 Location of study area.

\section{GEOLOGICAL SETTING}

The study area is located in the Lesser Himalaya (Fig. 1), which is bordered in the south by the Main Boundary Thrust (MBT) and in the north by the Main Central Thrust (MCT). The Lesser Himalaya is divisible into the Kathmandu Complex and the Nawakot Complex (Stöcklin and Bhattarai, 1977; Stöcklin, 1981). The study area includes the Bhimphedi Group of the Kathmandu Complex, and the Lower and the Upper Nawakot Groups of the Nawakot Complex. The Nawakot Complex and the Kathmandu Complex are separated by the Mahabharat Thrust (Stöcklin, 1980). The Lower Nawakot Group is subdivided into Kunchha Formation, Fagfog Quartzite, Dandagaun Phyllite, Nourpul Formation and the Dhading Dolomite in ascending order. The Upper Nawakot Group is subdivided into the Benighat Slate, Malekhu Limestone and the Robang Formation. The Nawakot Complex is composed exclusively of low grade meta-sediments. The Bhimphedi Group comprises meso- to high grade metamorphic rocks and has been divided into six formations: Raduwa Formation, Bhaisedobhan Marble, Kalitar Formation, Chisapani Quartzite, Kulekhani Formation and the Markhu Formation in ascending order from north to south (Fig. 2). The Tistung Formation belongs to the Phulchoki Group of the Kathmandu Complex.

The sedimentary structures such as ripple marks, graded and cross beds and mudcracks are found in Nawakot Complex (Stöcklin and Bhattarai, 1977; Stöcklin, 1980; Arita, 1983; Sakai, 1985; Sharma and Kizaki, 1989). In contrast, the sedimentary structures exposed in Fagfog Quartzite along the Malekhu-Thopal section show the overturned beds. 


\section{METHODOLOGY}

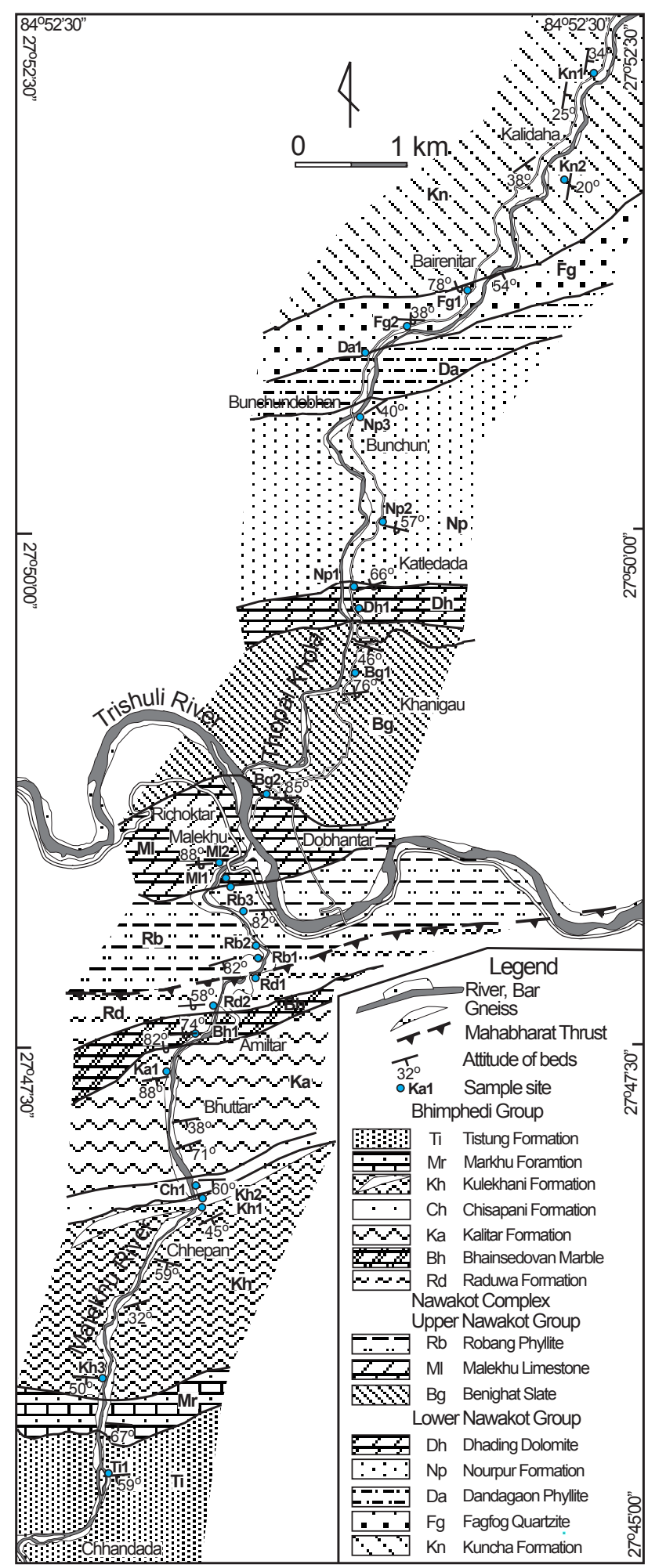

Fig. 2 Geological map along the study area.
Field studies have been carried out to study the lithological and structural variations in rock slopes. Twenty five locations were selected on the basis of exposures of the different lithology and the slope condition. Slopes at these locations were studied and classified for their rock mass quality. RMR was calculated by using five parameters, i.e., intact rock strength (UCS), Rock Quality Designation (RQD), spacing of discontinuity, condition of discontinuity and ground water condition. UCS was estimated in the field using a geological hammer. RQD was calculated by the equation (i) suggested by Palmstrom (2005) as below:

$$
\mathrm{RQD}=110-2.5 \mathrm{Jv}
$$

where, Jv is known as the volumetric joint count and is defined as the number of joints intersecting a volume of one cubic meter. Where the jointing occurs mainly as joint sets, the following equation was used:

$$
\mathrm{JV}_{\mathrm{V}}=1 / \mathrm{S} 1+1 / \mathrm{S} 2+1 / \mathrm{S} 3+\ldots \ldots 1 / \mathrm{Sn}+\mathrm{Nr} / 5 \ldots \ldots \ldots
$$

where, $\mathrm{S} 1, \mathrm{~S} 2$ and $\mathrm{S} 3$ are the average in spacing in meters for the joints sets, and $\mathrm{Nr} / 5$ is for random joint for spacing of $5 \mathrm{~m}$. After rating of all the parameters, RMR was computed according to the Bieniawski (1989) adding rating values of those five parameters:

$$
\mathrm{RMR}=\mathrm{R} 1+\mathrm{R} 2+\mathrm{R} 3+\mathrm{R} 4+\mathrm{R} 5 .
$$

where, R1=UCS, R2=RQD, R3=spacing of discontinuity, $\mathrm{R} 4=$ condition of discontinuity, and R5=groundwater condition.

Geological strength index (GSI) was calculated based on Sonmez and Ulusay (1999), and Osguoi et al. (2010) criteria. The former criterion provides a more quantitative numerical basis for evaluating GSI as a contributory use of the GSI system by introducing new parameters and ratings, such as Surface Condition Rating (SCR) and Structure Rating (SR) which are based on volumetric joint $(\mathrm{Jv})$ and estimated of the input parameter from RMR scheme (e.g. roughness, weathering and infilling). The second criterion is for very poor rock masses defined by a GSI value below 27 or 25 (Osguoi et al., 2010). In this system the term Broken Structure Domain (BSTR), Intact Core Recovery (ICR), and weathering (w) are used. With the help of these parameters SR and Joint Condition Index (JCI) were calculated. 
After the calculation of RMR and GSI values various graphical charts and bar diagrams were plotted to compare the geomechnical values of the formations with each other and also lithology versus RMR/GSI was plotted calculating a mean value of same lithology in the observation points of that area.

\section{LITHOLOGICAL UNITS AND THEIR ROCK MASS RATINGS}

Detailed engineering geological investigation was made on road cut sections and river cut section of varying slope heights that constitute the best outcrops for determining the lithological variation, weathering conditions, and geological characteristics of outcrops and rock excavation to record discontinuities and joints patterns (Fig. 3). The cut slopes have gentle to very steep dip angle with a developed system of joint. In general, the rock mass has been covered by soil of quaternary age with scanty vegetation.

The rock mass characteristics are described in the sequential order from the older rock formation of the Nawakot Complex to the younger formation, and then from the older formation of the Kathmandu Complex to the younger formation. The calculation of RMR has been performed for all twenty five locations (Table 1).

\section{Kunchha Formation}

The Kunchha Formation is the oldest rock unit of Lesser Himalaya, Central Nepal. It is well observed in

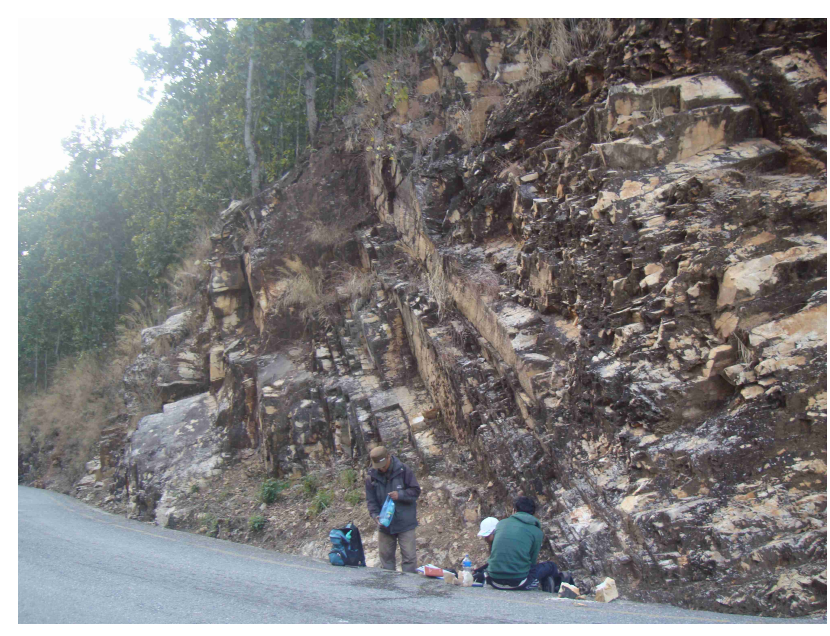

Fig. 3 Showing discontinuities along road cut section at location Fg1.
Kalidaha Area. It consist of intercalation of greenish grey crenulated phyllite, greenish grey gritty psammatic phyllite and fine- to coarse-grained, grey meta-sandstone approximately in equal ratio. The rock in this area is moderate to highly weathered with steep to gentle slopes.

As per the standard classification, RMR values at $\mathrm{Kn} 1$ and $\mathrm{Kn} 2$ are 57 and 50, respectively. Even though they lie in same formation and have same lithology, the variation of RMR is mainly due to the variation in ground water condition $(\mathrm{Kn} 1=15$ : completely dry, and $\mathrm{Kn} 2=7$ : wet condition). On the basis of geomechanical classification, the rock masses of the Kuncha Formation are classified as fair due to their soft lithology.

\section{Fagfog Quartzite}

This formation is also well exposed in along the Dhading road. This unit has a marker lithology with steep slope $\left(50^{\circ}-70^{\circ}\right.$ in study area) in the territory. It consists of moderately weathered, thin to thick milky white, coarsely crystalline quartzite. Due to its thickness and strongness the rock mass of both location ( $\mathrm{Fg} 1$ and $\mathrm{Fg} 2$ ) lies in good category according to RMR classification and GSI value shows that its lies in blocky/disturbed and fair discontinuity surface. RMR value in the location $\mathrm{Fg} 1$ is 62 and $\mathrm{Fg} 2$ is 70 , both which indicate good rocks. Difference in RQD (Fg1=17 good, $\mathrm{Fg} 2=20$ excellent), persistence and roughness (higher ratings in Fg2 compared to Fg1), and ground water condition (Fg1 damp and Fg2 completely dry) affects variation in RMR.

\section{Dandagaun Phyllite}

It comprises of mainly very poor rock mass. It consist of succession of bluish grey to lead grey, soapy, finely foliated pelitic phyllite intercalated with grey, fine grained psammatic phyllite $(1: 1)$. Thin bands of grey to dirty white, fine-grained quartzites and grey to dark grey dolomites are minors. Due to the presence of soft rock phyllite in the location Da1, the RMR value is 49 that lies in fair rock. GSI value is only 16.6 and lies in poorly interlocked, heavily broken rock mass (Fig. 4).

\section{Nourpul Formation}

It comprises moderate to slightly weathered, medium to thick bedded, light grey to white, medium to coarsely crystalline quartzite with greenish grey, crenulated soapy 
Table 1: Rock Mass Rating (RMR) in the study area ( Bieniawski,1989)

\begin{tabular}{|c|c|c|c|c|c|c|c|c|c|c|c|c|}
\hline \multirow[t]{2}{*}{ Location } & & \multirow[t]{2}{*}{$\begin{array}{l}\mathrm{a} \mathrm{R} 1 \\
\end{array}$} & \multirow[t]{2}{*}{$\mathrm{R} 2$} & \multirow[t]{2}{*}{ R3 } & \multicolumn{5}{|c|}{$\mathrm{R} 4$} & \multirow[t]{2}{*}{ R5 } & \multirow[t]{3}{*}{ RMR } & \multirow[t]{2}{*}{ Remarks } \\
\hline & & & & & \multicolumn{2}{|c|}{${ }^{\mathrm{b}}$ Persistency ${ }^{\mathrm{c}}$ Aperture } & \multirow{2}{*}{$\begin{array}{l}{ }^{\mathrm{d}} \text { Roughness } \\
\mathrm{R} \text { to } \mathrm{S}\end{array}$} & \multirow{2}{*}{$\begin{array}{l}{ }^{\mathrm{e}} \text { Filling } \\
\mathrm{N} \text { to } \mathrm{H}>5 \mathrm{~mm}\end{array}$} & ${ }^{\mathrm{f}}$ Weathering & & & \\
\hline Kn1 & Grn. grey phyllite intercalated & VS to MS & Good & mod. to close & $\mathrm{L}$ to $\mathrm{H}$ & $\mathrm{MO}$ to $\mathrm{O}$ & & & $\mathrm{S}$ to $\mathrm{M}$ & C. dry & & \\
\hline Rating & with g & 8 & 13 & 9 & 1 & 2 & 2 & 3 & 4 & 15 & 57 & good \\
\hline $\mathrm{Kn} 2$ & Highly sheared, folded phyllite & Strong & Fair & wide to close & $\mathrm{M}$ to $\mathrm{VH}$ & MO to VW & $\mathrm{R}$ to $\mathrm{S}$ & $\mathrm{S}>5 \mathrm{~mm}$ to $\mathrm{N}$ & M & wet & & \\
\hline Rating & with & 7 & 13 & 11 & 1 & 2 & 3 & 3 & 3 & 7 & 50 & Fair \\
\hline $\mathrm{Fg} 1$ & Thin to med. bedded white & VS to MS & Good & mod. to close & $\mathrm{L}$ to $\mathrm{H}$ & $\mathrm{T}$ to $\mathrm{O}$ & $\mathrm{Sl}$ & $\mathrm{H}<$ or $>5 \mathrm{~mm}$ & $\mathrm{~S}$ to $\mathrm{M}$ & Damp & & \\
\hline Rating & coars & 12 & 17 & 10 & 1 & 4 & 1 & 4 & 3 & 10 & 62 & good \\
\hline $\mathrm{Fg} 2$ & Medium to thick bedded white & VS to MS & Excellent & wide to mod. & $\mathrm{H}$ to $\mathrm{VH}$ & $\mathrm{O}$ to $\mathrm{VW}$ & $\mathrm{R}$ to $\mathrm{S}$ & $\mathrm{S}<5 \mathrm{~mm}$ & M & C. dry & & \\
\hline Rating & quartzite & 12 & 20 & 12 & 1 & 1 & 4 & 2 & 3 & 15 & 70 & good \\
\hline Da1 & Dark grey to black, wavy calc. & MS & V. poor & mod. to close & $\mathrm{H}$ & None to VW & $\mathrm{R}$ to $\mathrm{SR}$ & $\mathrm{N}$ to $\mathrm{S}>5 \mathrm{~mm}$ & S & Damp & & \\
\hline Rating & phyllite with quartz vein & 4 & 8 & 9 & 1 & 4 & 4 & 4 & 5 & 10 & 49 & fair \\
\hline Np1 & Coarsly xlline, green grey, pink & $\mathrm{S}$ to $\mathrm{VS}$ & poor & mod. to close & $\mathrm{L}$ to $\mathrm{VH}$ & $\mathrm{T}$ to $\mathrm{O}$ & $\mathrm{R}$ to $\mathrm{S}$ & $\mathrm{N}$ to $\mathrm{S}<5 \mathrm{~mm}$ & $\mathrm{~S}$ to $\mathrm{M}$ & Damp & & \\
\hline Rating & quartz & 9 & 8 & 9 & 2 & 4 & 2 & 4 & 4 & 10 & 52 & fair \\
\hline $\mathrm{Np} 2$ & Finely xlline, d. grey quartzite & S & Fair & mod. to close & $\mathrm{H}$ & $\mathrm{O}$ to $\mathrm{VW}$ & VR to SR & $\mathrm{St}<$ or $>5 \mathrm{~mm}$ & M & Damp & & \\
\hline Rating & with thinly d. grey phyllite & 7 & 13 & 9 & 1 & 1 & 4 & 1 & 3 & 10 & 49 & fair \\
\hline $\mathrm{Np} 3$ & Massive, coarse, pink and 1. & VS to MS & Good & wide to close & $\mathrm{L}$ to $\mathrm{H}$ & MO to VW & $\mathrm{R}$ to $\mathrm{VR}$ & $\mathrm{N}$ to $\mathrm{S}>5 \mathrm{~mm}$ & $\mathrm{~S}$ to $\mathrm{M}$ & Damp & & \\
\hline Rating & grey quartzite with phyllite & 10 & 17 & 10 & 1 & 2 & 6 & 4 & 4 & 10 & 64 & good \\
\hline Dh1 & Laminated light grey finely & $\mathrm{S}$ & V. poor & mod. to close & $\mathrm{L}$ to $\mathrm{H}$ & $\mathrm{T}$ & $\mathrm{R}$ to $\mathrm{SR}$ & $\mathrm{N}$ & S & Damp & & \\
\hline Rating & crystalline dolomi & 7 & 3 & 8 & 3 & 5 & 5 & 6 & 5 & 10 & 52 & fair \\
\hline $\mathrm{Bg} 1$ & Thinly foliated dark-grey to & MS & V. poor & very close & $\mathrm{L}$ to $\mathrm{H}$ & VT to $\mathrm{T}$ & $\mathrm{R}$ to $\mathrm{SR}$ & $\mathrm{N}$ & M & Dripping & & \\
\hline Rating & black cal. slate & 4 & 3 & 5 & 3 & 5 & 5 & 6 & 3 & 4 & 38 & poor \\
\hline $\mathrm{Bg} 2$ & Thinly foliated grey slate with & MS & V. poor & very close & $\mathrm{L}$ to $\mathrm{VH}$ & $\mathrm{MO}$ to $\mathrm{O}$ & $\mathrm{R}$ to $\mathrm{SR}$ & $\mathrm{N}$ to $\mathrm{S}<5 \mathrm{~mm}$ & M & wet & & \\
\hline Rating & some quartz lenses of boudins & 4 & 3 & 5 & 2 & 3 & 5 & 4 & 3 & 7 & 36 & poor \\
\hline M11 & Laminated, finely crystalline, & VS to MS & poor & close & $\mathrm{H}$ & MO to VW & $\mathrm{S}$ to $\mathrm{R}$ & $\mathrm{N}$ to $\mathrm{S}>5 \mathrm{~mm}$ & S & C. dry & & \\
\hline Rating & da & 12 & 8 & 8 & 2 & 2 & 1 & 4 & 5 & 15 & 57 & fair \\
\hline M12 & Laminated, finely crystalline, & VS to MS & Fair & close-v.close & $\mathrm{M}$ to $\mathrm{VH}$ & $\mathrm{T}$ to $\mathrm{VW}$ & $\mathrm{R}$ to $\mathrm{S}$ & $\mathrm{N}$ to $\mathrm{S}>5 \mathrm{~mm}$ & S & Damp & & \\
\hline Rating & & 12 & 13 & 9 & 1 & 2 & 3 & 2 & 5 & 10 & 57 & fair \\
\hline $\mathrm{Rb} 1$ & Med. to coarse quartzite, with & ES & V. poor & mod. to close & $\mathrm{H}$ to $\mathrm{VH}$ & VT to VW & $\mathrm{R}$ to $\mathrm{Sl}$ & $\mathrm{N}$ to $\mathrm{S}>5 \mathrm{~mm}$ & S & C. dry & & \\
\hline Rating & bands & 15 & 3 & 9 & 1 & 4 & 1 & 4 & 5 & 15 & 57 & fair \\
\hline $\mathrm{Rb} 2$ & Greenish grey schist with & S & Fair & mod. to close & $\mathrm{H}$ to $\mathrm{VH}$ & VW & $\mathrm{R}$ to $\mathrm{SR}$ & $\mathrm{S}<\mathrm{or}>5 \mathrm{~mm}$ & S & Damp & & \\
\hline Rating & quartz & 7 & 8 & 9 & 1 & 0 & 4 & 1 & 5 & 10 & 45 & fair \\
\hline $\mathrm{Rb} 3$ & with sericitic partings, & VS & Fair & wide to close & VL to VH & $\mathrm{MO}$ to $\mathrm{O}$ & $\mathrm{R}$ to $\mathrm{SR}$ & $\mathrm{S}<5 \mathrm{~mm}$ & S & Damp & & \\
\hline Rating & artz vein & 12 & 17 & 12 & 1 & 3 & 4 & 2 & 5 & 10 & 66 & good \\
\hline $\mathrm{Rd} 1$ & Greenish grey, biotite & strong & Excellent & wide to mod. & $\mathrm{H}$ to $\mathrm{VH}$ & VW & VR to SR & $\mathrm{S}>5 \mathrm{~mm}$ & S & Damp & & \\
\hline Rating & garneti & 7 & 20 & 12 & 1 & 0 & 5 & 0 & 5 & 10 & 60 & fair \\
\hline $\mathrm{Rd} 2$ & Dark grey schist intercalated & strong & Fair & moderate & $\mathrm{VL}$ to $\mathrm{VH}$ & VW & $\mathrm{R}$ to $\mathrm{SR}$ & $\mathrm{S}>5 \mathrm{~mm}$ & M & Damp & & \\
\hline Rating & with st & 7 & 13 & 10 & 3 & 0 & 4 & 0 & 3 & 10 & 50 & fair \\
\hline $\mathrm{Bh} 1$ & White crystalline marble with & strong & Fair & mod. to close & $\mathrm{L}$ to $\mathrm{VH}$ & VW & $\mathrm{R}$ to $\mathrm{SR}$ & $\mathrm{S}>5 \mathrm{~mm}$ & $\mathrm{~S}$ to $\mathrm{M}$ & Damp & & \\
\hline Rating & schis & 7 & 13 & 9 & 3 & 0 & 4 & 0 & 3 & 10 & 49 & fair \\
\hline Ka1 & Highly foliated and wavy d. grey & MS & Fair & mod. to close & $\mathrm{M}$ to $\mathrm{VH}$ & VW & VR to $\mathrm{R}$ & $\mathrm{S}>5 \mathrm{~mm}$ & M & dripping & & \\
\hline Rating & biotite & 4 & 13 & 8 & 1 & 0 & 6 & 0 & 3 & 4 & 39 & poor \\
\hline Ch1 & L. grey to white quartzite with & strong & Fair & wide to close & $\mathrm{L}$ to $\mathrm{VH}$ & VW & $\mathrm{R}$ to $\mathrm{SR}$ & $\mathrm{S}>5 \mathrm{~mm}$ & S & C. dry & & \\
\hline Rating & & 7 & 13 & 11 & 2 & 0 & 5 & 0 & 5 & 15 & 58 & fair \\
\hline Kh1 & Thn. foliated dark grey biotite & strong & Excellent & mod.-v. close & $\mathrm{L}$ to $\mathrm{H}$ & VT to VW & $\mathrm{R}$ to $\mathrm{SR}$ & $\mathrm{N}$ to $\mathrm{S}>5 \mathrm{~mm}$ & $\mathrm{~S}$ & Damp & & \\
\hline Rating & ind garnet & 7 & 20 & 8 & 2 & 4 & 4 & 4 & 5 & 10 & 64 & good \\
\hline $\mathrm{Kh} 2$ & Massive augen gneiss & ES & Excellent & v. wide & $\mathrm{H}$ to $\mathrm{VH}$ & VW & $\mathrm{VR}$ to $\mathrm{R}$ & $\mathrm{S}>5 \mathrm{~mm}$ & S & c. dry & & \\
\hline Rating & & 15 & 20 & 20 & 1 & 0 & 6 & 0 & 5 & 15 & 82 & v. good \\
\hline $\mathrm{Kh} 3$ & D. grey biotite schist and grey & VS & Fair & mod.to close & $\mathrm{L}$ to $\mathrm{VH}$ & VT to $\mathrm{T}$ & SR to $S$ & $\mathrm{~N}$ to $\mathrm{S}<5 \mathrm{~mm}$ & S & Damp & & \\
\hline Rating & & 12 & 13 & 9 & 1 & 5 & 1 & 3 & 5 & 10 & 59 & fair \\
\hline Til & D. grey laminated metasanstone & strong & Good & wide to mod. & $\mathrm{H}$ to $\mathrm{VH}$ & VW & $\mathrm{R}$ & $\mathrm{S}>5 \mathrm{~mm}$ & S & wet & & \\
\hline Rating & with phyllite partings & 7 & 13 & 11 & 1 & 0 & 5 & 0 & 5 & 7 & 48 & fair \\
\hline
\end{tabular}

$\mathrm{Kn}=$ Kuncha Formation; Fg = Fagfog Quartzite; $\mathrm{Da}=$ Dandagaon Phyllite; $\mathrm{Np}=$ Nourpur Formation, $\mathrm{Dh}=$ Dhading Dolomite; $\mathrm{Bg}=$ Benighat Slate; $\mathrm{Ml}=\mathrm{Malekhu}$ Limestone; $\mathrm{Rb}=\mathrm{Robang}$ Formation; $\mathrm{Rd}=$ Raduwa Formation; $\mathrm{Ka}=$ Kalitar Formation, $\mathrm{Ch}=$ Chisapani Quartzite; $\mathrm{Kh}=$ Kulekhani Formation, $\mathrm{Ti}=$ Tistung Formation

$\mathrm{R} 1=$ strength in intact rock material; R2= Rock Quality Desingnation; $\mathrm{R} 3=$ spacing of discontinuiteis; $\mathrm{R} 4=$ condition of discontinuities; $\mathrm{R} 5=$ ground water

RMR value (Bieniawski, 1989): $<21$ very poor rock; 21-40 poor rock; 41-60 fair rock; 61-80 good rock; 81-100 very good rock

${ }^{\text {a }} \mathrm{R} 1$ : MS = moderately strong; $\mathrm{S}=$ strong; $\mathrm{VS}=$ very strong; $\mathrm{ES}=$ extremely strong

${ }^{\mathrm{b}}$ Persistency: VL=very low; $\mathrm{L}=$ low; $\mathrm{M}=$ medium; $\mathrm{H}=$ high, $\mathrm{VH}=$ =ery high

${ }^{c}$ Aperture: $\mathrm{O}=$ open; $\mathrm{MO}=$ =moderately open; $\mathrm{W}=$ wide; $\mathrm{VW}=$ =ery wide; $\mathrm{T}=$ tight; $\mathrm{VT}=$ =very tight

d Roughness: $\mathrm{S}=$ =smooth; $\mathrm{SR}=$ slightly rought; $\mathrm{R}=$ rough; $\mathrm{vR}=$ very rought; $\mathrm{Sl}=$ =slickenside;

${ }^{e}$ Filling: $\mathrm{H}=$ hard; $\mathrm{S}=$ soft; $\mathrm{N}=$ none

${ }^{\mathrm{f}}$ Weathering: $\mathrm{S}=$ slight; $\mathrm{M}=$ moderate; 


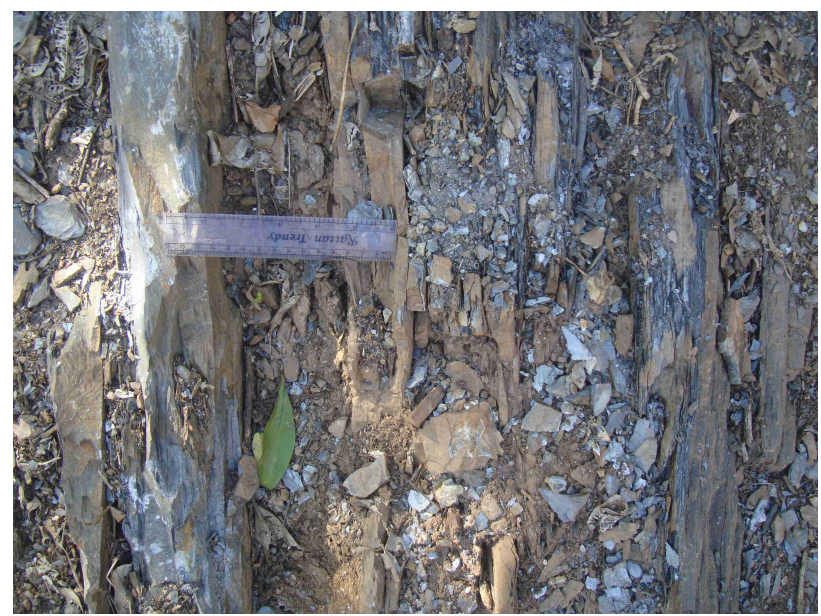

Fig. 4 Poor rock mass at the location Da1.

phyllite. The rock masses are fair and blocky/disturbed with fair discontinuity surface. Np1 and Np2 have almost similar RMR values, 52 and 49, respectively, and can be classified as fair rock, but in location Np3 it is 64 and is categorized as a good rock mass. The intact rock strength and RQD are higher for quartzites of $\mathrm{Np} 3$ compared to $\mathrm{Np} 1$ and $\mathrm{Np} 2$, thus contributing towards its better rating.

\section{Dhading Dolomite}

This formation consists of grey, siliceous, thin to medium bedded dolomite and is thinly intercalated with calcareous phyllite and metasandstone. The rock mass of this area is highly jointed and fractured that's why its RQD value is very low and categorized in fair rock mass. In Dh1, RMR is 52 (fair rock). Even the RQD is very low in this location, lack of aperture and infill material and UCS of intact rock have increased its RMR value.

\section{Benighat Slate}

This formation also consist of very poor rock masses of dark-grey to charcoal black slates with frequent intercalation of siliceous dolomite. Slates of this unit are also intercalated with grey to dark grey colored limestone. Abundant quartz veins and boudinage structures were observed parallel to the finely foliated charcoal slate. Due to very poor rock mass, the RQD value lies in very poor quality. The strength of the intact rock is also medium strong and the ground water condition is damp to dripping. Due to these conditions, the rock mass of this formation is classified as poor and disintegrated, poorly interlocked rock masses. In $\mathrm{Bg} 1$ and $\mathrm{Bg} 2$ the RMR values are 38 and 36 , respectively, and both are classified as poor rocks.
Due to the low UCS value, RQD and high ground water condition, the rock of this area is determined as poor.

\section{Malekhu Limestone}

This formation consists of slightly weathered, thin to medium bedded, laminated, yellowish grey, silicious dolomite with thinly partings of bluish, soapy phyllite. The strength of the intact rock this formation is high (100-250Mpa) although it has poor to fair quality of RQD and its water condition is damp to completely dry. Due to these main conditions it has RMR value 57, i.e. fair rock mass. In the locations M11 and M12, RMR values are same, 57. Although they have same RMR value, some of the parameters inside them are different from each other. RQD is poor in M11 but fair in M12 having a rating of 13 . Not only the RQD but also the ground water condition is different viz. M11 rock is completely dry whereas M12 rock is somewhat damp.

\section{Robang Formation}

This formation is well exposed along the Malekhu Khola section near the Mahabharat Thrust (MT) by which Nawakot Complex and Kathmandu Complex are being separated. It comprises thin to medium laminated white quartzite and occasionally occurs with chlorite schist and partings of phyllite. In this formation detail observation is taken in three locations ( $R b 1, R b 2$, and $R b 3$ ) on the basis of different conditions of parameters. Rb1 has extremely strong intact rock material and completely dry but it has dominantly smooth roughness of joints and very low RQD value due to the highly jointed and low spacing between joint set. $\mathrm{Rd} 2$ comprises dominantly schist in comparison to quartz (Fig. 5) thus it has only strong intact rock, damp condition, and wide aperture with soft fillings but has Fair quality of RQD. Rb3 has very strong intact rock, fair quality of RQD due to high spacing and rough surface in comparison to previous two locations. In the course of classifying them, Rb3 has good quality of rock and the rest are fair. RMR of Rb1, $\mathrm{Rb} 2$ and $\mathrm{Rb} 3$ are 57, 45, and 62 respectively, and they lie in fair to good quality. Strength of intact rock material is extremely strong in Rb1, just strong in Rb2 and very strong in Rb3. The RQD value is very poor in Rb1 but is fair in both $\mathrm{Rb} 2$ and $\mathrm{Rb} 3$. Roughness rating is also low in $\mathrm{Rb} 1$ in comparison to $\mathrm{Rb} 2$ and $\mathrm{Rb} 3$. Although the other parameters of $\mathrm{Rb} 1$ are equal or greater, it is classified 


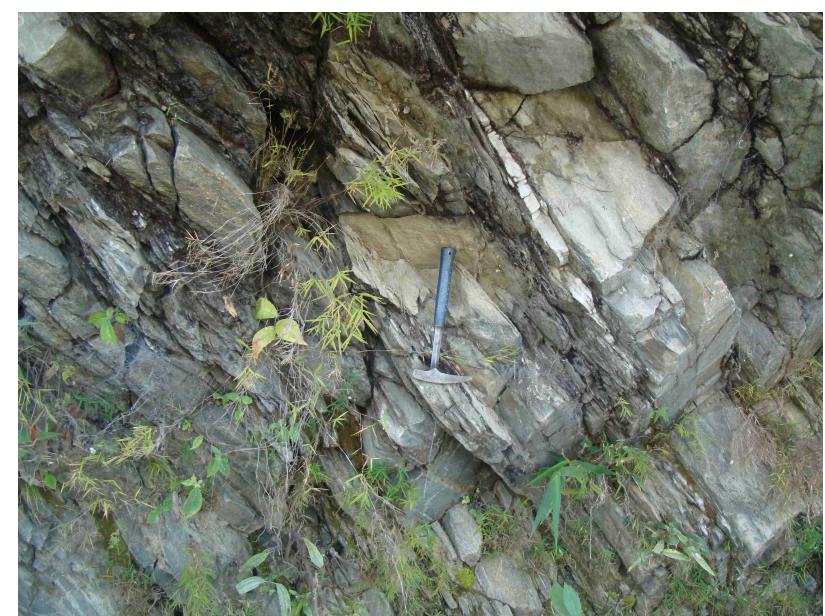

Fig. 5 showing the discontinuities of rock mass in $\mathrm{Rb} 2$. as fair due to the less RQD. Same as in Rb2, UCS, aperture, and groundwater condition have played a major role to diminish RMR value. But in Rb3, although the rock is damp, the other parameters are equal or greater than that of Rb1 and Rb2, that's why Rb3 can be classified as good one.

\section{Raduwa Formation}

This formation comprises garnetiferous schist. Schist is psammatic as well as pellitic and is calcareous. Folded quartz veins and boudins indicate highly shared zone. The detail observation is taken at two locations; Rd1 and Rd2. Rd1 and Rd2 have RMR value 60 and 50 respectively and can be categorized as fair rocks. UCS, aperture, infill material and ground water condition are same in both of these location but other parameters are more or less greater in $\mathrm{Rd} 1$ than that in $\mathrm{Rd} 2$, except persistency that is high in $\operatorname{Rd} 2$.

\section{Bhainsedobhan Marble}

It comprises medium to thick bedded, coarsely crystalline, white marble occasionally intercalated with biotite-pellitic schist. Bh1 has RMR 49 and is classified as fair rock. In this location UCS of intact rock, RQD, roughness, and groundwater condition have played a main role to classify its rock as fair one.

\section{Kalitar Formation}

It comprises highly foliated, dark colored, biotite containing psammatic schist intercalated with light grey, fine quartzite with quartz veins. It has poor quality of rock masses due to its low strength of intact rock, fair quality of RQD, very wide aperture with soft fillings and dripping water condition. Kal has RMR value 39 which is classified as poor rock. Here the strength of intact rock material is medium strong, aperture is very wide and groundwater condition is dripping that's why its rock is categorized into poor rock although it has fair quality of RQD.

\section{Chisapani Quartzite}

It consists of thin to medium thick bedded, coarse grained, non-calcareous milky white quartzite intercalated with dark grey, fine grained, well laminated, finely foliated, biotite containing psammatic schist. Although the rock mass of this location has very wide aperture with soft feelings and less strength of intact rock, it has fair quality of RQD with close to wide separation and completely dry condition categorized it as fair rock mass. Ch1 has RMR value 58 (fair rock). Although the aperture is very wide and infill material is soft that has thickness greater than $5 \mathrm{~mm}$, the completely dry condition of the rock, high RQD and spacing have played a major role to classify it as fair rock.

\section{Kulekhani Formation}

This formation consist of slightly weathered, massive augen Gneiss (Fig. 6a), as well as medium bedded, light grey to ash grey, coarse grain quartzite intebedded with the micaceous schist, garnetiferous schist (Fig. 6b). Schist is pellitic as well as psammatic. In this formation detail observation is taken in three different locations, Kh1, Kh2, and Kh3. Kh1, Kh2, and Kh3 have RMR values of 64 (good rock), 82 (very good rock), and 59 (fair rock), respectively. Kh1 and Kh2 have excellent Quality of RQD of rating 20. Kh1 contains strong schist with excellent RQD value and has very tight to very wide aperture, rough to very rough surface resulting the good rock masses. Although Kh1 has aperture rating and infill rating 4 and 4, respectively, and Kh2 has 0 in both, other parameters, such as RQD, spacing and weathering grade have high ratings for Kh2. Thus, Kh2 has high RMR value due to the extremely strong intact rock, excellent quality RQD, very wide spacing, roughness, weathering grade and completely dry condition. Kh3 has fair rock because it contains very strong intact rock strength, fair RQD, very tight joint, II grade of weathering and damp 

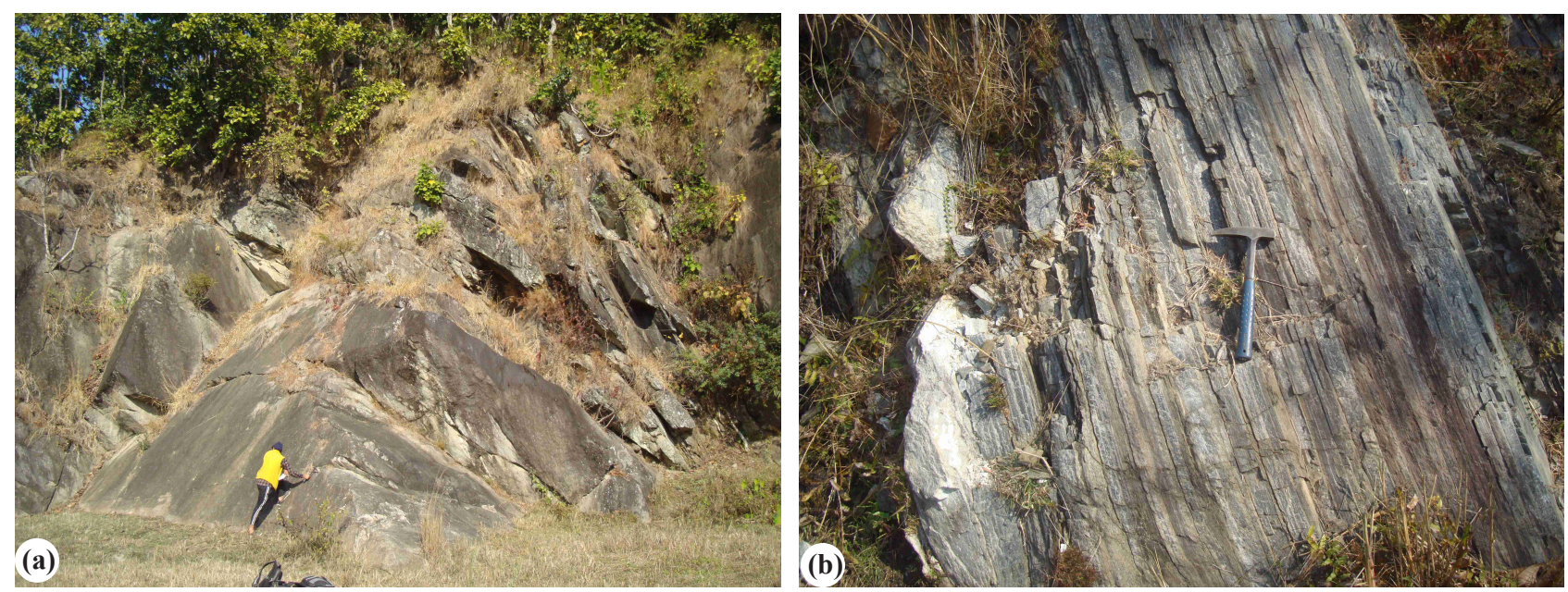

Fig. 6 Photographs: (a) Showing massive bed of Kh2, and (b) Showing the bed of Kh1.

water condition.

\section{Markhu Formation}

It consists of highly weathered, coarsely crystalline marble, greenish grey pellitic and psammatic phyllite, greenish grey micaceous schist occasionally intercalated with meta-sandstone. Due to the reason of high weathering, detail study for geomechanical classification couldn't be conducted.

\section{Tistung Formation}

It is mainly composed of thin to thick, grey, medium to coarse grained light grey to ash grey, pellitic phyllite interbedded with dark grey laminated meta-sandstone. It has fair rock mass due to less strong intact rock, medium to high persistence, very wide aperture with soft filling and wet condition. RMR of Til is 48 (fair rock). It contains strong intact rock, good quality of RQD, wide to moderate joint spacing and slightly weathering condition which have played a main role to categorize its rock into fair one.

As a whole, the highest RMR value is found to be 82 (very good rock) in $\mathrm{Kh} 2$ and the lowest value is found to be 36 (poor rock) in Bg2 (Fig. 7). The poor rock categories are shown by $\mathrm{Bg} 1$ and $\mathrm{Bg} 2$, the fair rock categories are shown by Nk2, Da1, Np1, Np2, Dh1, M11, Ml2, Rb1, Rb2, Rd1, Rd2, Bh1, Ch1, Kh3, and Ti1. Good quality rocks are $\mathrm{Kn} 1, \mathrm{Fg} 1, \mathrm{Fg} 2, \mathrm{Da} 2, \mathrm{Rb3}$, and $\mathrm{Kh} 1$. Very good quality rock is shown by Kh2.

\section{ESTIMATION OF GEOLOGICAL STRENGTH INDEX}

Geological strength index (GSI) was calculated based on Sonmez and Ulusay (1999), and Osguoi et al. (2010) criteria. The calculation of GSI also has been performed for all twenty five locations and the detail ratings for GSI are given in Table 2 and Table 3.

As per the standard classification, GSI values at Kn1 and $\mathrm{Kn} 2$ are $37 \pm 3$ and $36 \pm 3$, respectively. The Jv value of $\mathrm{Kn} 1$ is 17.631 and of $\mathrm{Kn} 2$ is 23.43 , and both locations have same SCR value. That's why there is no huge difference in GSI value in these two locations. Rock masses of both locations lie on blocky/disturbed-folded and/or faulted with angular blocks formed by many intersecting discontinuity sets and fair viz, smooth, moderately weathered or altered surface in the chart as shown in Fig. 8.

The $\mathrm{Jv}$ values are 8.485 and 6.835 in locations $\mathrm{Fg} 1$ and $\mathrm{Fg} 2$, respectively, and the SCR values are 8 and 9, respectively. Thus, GSI value of $\mathrm{Fg} 1$ is $40 \pm 3$ and of Fg2 is $44 \pm 3$. Rock masses of both locations also lie on blocky/disturbed-folded and/or faulted with angular blocks formed by many intersecting discontinuity sets and fair viz, smooth, moderately weathered or altered surface in the chart.

The rock mass of the location Da1 lies in poor rock mass so the GSI value is calculated on the basis of Osgoui et al. (2010) criterion. According to this criterion, the JV value in this location is 40 and IJC is 13.5 , which gives GSI value of $23 \pm 3$. This value can be classified as 


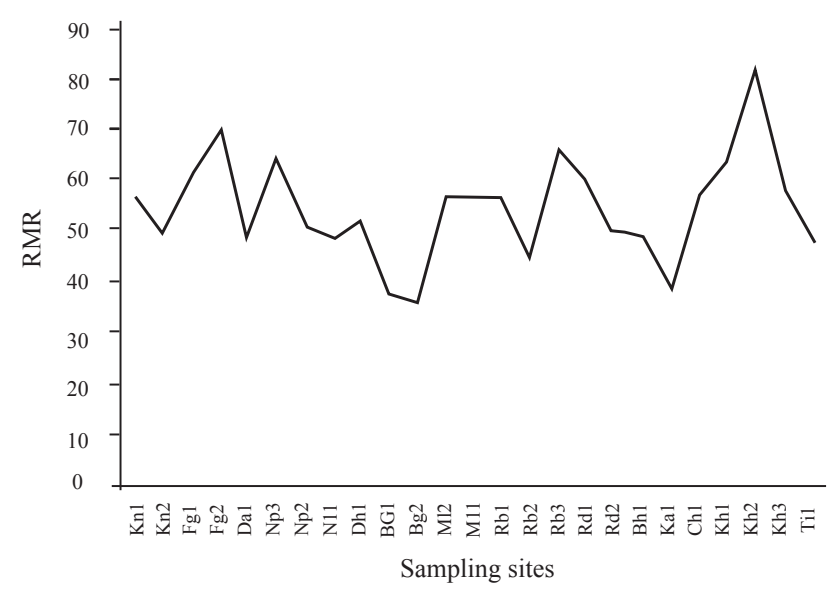

Fig. 7 Graphical representation of RMR in the study area.

disintegrated-poorly interlocked, heavily broken mass with mixture or angular and rounded rock pieces and is shown in Fig. 9.

The Jv values of $\mathrm{Np} 1, \mathrm{~Np} 2$ and $\mathrm{Np} 3$ are 28.09 and 20.34 , and 11.55 , SCR are 10,8 , and 14 , respectively. Thus, the GSI value of Np3 (52 \pm 3 ) is the greates among

Table 2: Geological Strength Index (GSI) in the study area (Sonmez and Ulusay, 1999)

\begin{tabular}{llllllll}
\hline Location & Jv & SR & Rr & Rw & Rf & SCR & GSI \\
\hline Kn1 & 17.631 & 30 & 2 & 4 & 3 & 9 & $37 \pm 3$ \\
Kn2 & 23.43 & 30 & 3 & 3 & 3 & 9 & $36 \pm 3$ \\
Fg1 & 8.485 & 54 & 1 & 3 & 4 & 8 & $40 \pm 3$ \\
Fg2 & 6.835 & 60 & 4 & 3 & 2 & 9 & $44 \pm 3$ \\
Np1 & 28.09 & 28 & 2 & 4 & 4 & 10 & $38 \pm 3$ \\
Np2 & 20.34 & 30 & 4 & 3 & 1 & 8 & $34 \pm 3$ \\
Np3 & 11.55 & 48 & 6 & 4 & 4 & 14 & $52 \pm 3$ \\
M11 & 27.99 & 27 & 1 & 5 & 4 & 10 & $38 \pm 3$ \\
M12 & 16.22 & 36 & 3 & 5 & 2 & 10 & $40 \pm 3$ \\
Rb1 & 35.96 & 22 & 1 & 5 & 4 & 10 & $37 \pm 3$ \\
Rb2 & 24.77 & 28 & 4 & 5 & 1 & 10 & $38 \pm 3$ \\
Rb3 & 13.40 & 22 & 4 & 5 & 2 & 11 & $38 \pm 3$ \\
Rd1 & 3.98 & 67 & 5 & 5 & 0 & 10 & $49 \pm 3$ \\
Rd2 & 16.56 & 18 & 4 & 3 & 0 & 8 & $32 \pm 3$ \\
Bh1 & 25.42 & 28 & 4 & 3 & 0 & 7 & $32 \pm 3$ \\
Ka1 & 23.76 & 30 & 6 & 3 & 0 & 9 & $37 \pm 3$ \\
Ch1 & 18.26 & 18 & 5 & 5 & 0 & 10 & $36 \pm 3$ \\
Kh1 & 61.67 & 19 & 4 & 5 & 4 & 13 & $42 \pm 3$ \\
Kh2 & 1.07 & 83 & 6 & 5 & 0 & 11 & $58 \pm 3$ \\
Kh3 & 20.00 & 32 & 1 & 5 & 3 & 9 & $37 \pm 3$ \\
Ti1 & 18.26 & 33 & 5 & 5 & 0 & 10 & $38 \pm 3$ \\
\hline Jv=Joint volume, SR= Structure Rating(SR=79.8-17.5InJv), \\
Rr= Roughness Rating, Rw= Weathering Rating, \\
Rf=Infill material Rating, & & \\
SCR= Surface Condition Rating(SCR=Rr+Rw+Rf) & \\
& & & & & &
\end{tabular}

the rock masses, and is classified as very blockyinterlocked and partially disturbed rock mass with multifaced angular blocks formed by by four or more discontinuity sets and good surface condition viz, smooth, slightly weathered, iron stained surface. GSI of $\mathrm{Np} 1$ is $38 \pm 3$, and that of $\mathrm{Np} 2$ is $34 \pm 3$, and both are classified as blocky/disturbed-folded and/or faulted with angular blocks formed by many intersecting discontinuity sets and fair viz, smooth, moderately weathered or altered surface in the chart.

The location Dh1 also lies in poor rock masses so the GSI value is calculated on the basis of Osgoui et al.,(2010) criterion. This criterion has given the $50 \mathrm{Jv}$ value in this location. SR of 13.66 and IJC of 6.5 that gives GSI value of $16 \pm 3$ can be classified as disintegrated-poor rock mass as a result of intense jointing.

$\mathrm{Bg} 1$ and $\mathrm{Bg} 2$ have also poor rock masses that have highest $\mathrm{Jv}$ values, 60 and 72.7. The $\mathrm{SR}$ of $\mathrm{Bg} 1$ and $\mathrm{Bg} 2$ are 10.82 and 7.8, respectively and IJC of the same are 11 and 6 , respectively. Therefore, the GSI values for $\mathrm{Bg} 1$ and $\mathrm{Bg} 2$ are $18.5 \pm 3$ and $13.5 \pm 3$, respectively and the former is categorized into disintegrated-poor rock mass as a result of intense jointing and the second one into very poor, extremely crushed/sheared rock mass.

Locations M11 and M12 have GSI values of $38 \pm 3$ and $40 \pm 3$, respectively. Both locations have same Surface Condition Rating (SCR) of 10 but different Jv values of 27.99 and 16.22 , respectively. Therefore there is no huge difference of GSI value and they lie in same blocky/disturbed-folded and/or faulted with angular blocks formed by many intersecting discontinuity sets and fair viz, smooth, moderately weathered or altered surface in the chart.

$\mathrm{Rb} 1, \mathrm{Rb} 2$, and $\mathrm{Rb} 3$ have almost similar values of GSI viz, $37 \pm 3,38 \pm 3$, and $38 \pm 3$, respectively and Jv are 35.96 , 24.77 and 13.4 that give SR values of 22,28 , and 22,

Table 3: Geological Strength Index(GSI) in the study area (After Osgoui et al., 2010)

\begin{tabular}{lllllllll}
\hline \multirow{2}{*}{ Locaiton } & Dn & $\mathrm{Sb}$ & $\begin{array}{l}\mathrm{Jv}=\mathrm{Dn} \\
(1 / \mathrm{Sb})\end{array}$ & *SR & BSTR & W & IJC & GSI \\
\hline Da1 & 3 & 0.075 & 40 & 17.13 & 6 & 7 & 13.5 & $23 \pm 3$ \\
Dh1 & 4 & 0.08 & 50 & 13.66 & 6 & 7 & 6.5 & $16.6 \pm 3$ \\
Bg1 & 3 & 0.05 & 60 & 10.82 & 4 & 6 & 11 & $18.5 \pm 3$ \\
Bg2 & 4 & 0.055 & 72.7 & 7.8 & 6 & 6 & 6 & $13.5 \pm 3$ \\
\hline
\end{tabular}

$* \mathrm{SR}=-15.58 \operatorname{In}(\mathrm{Jv})+74.61$ 


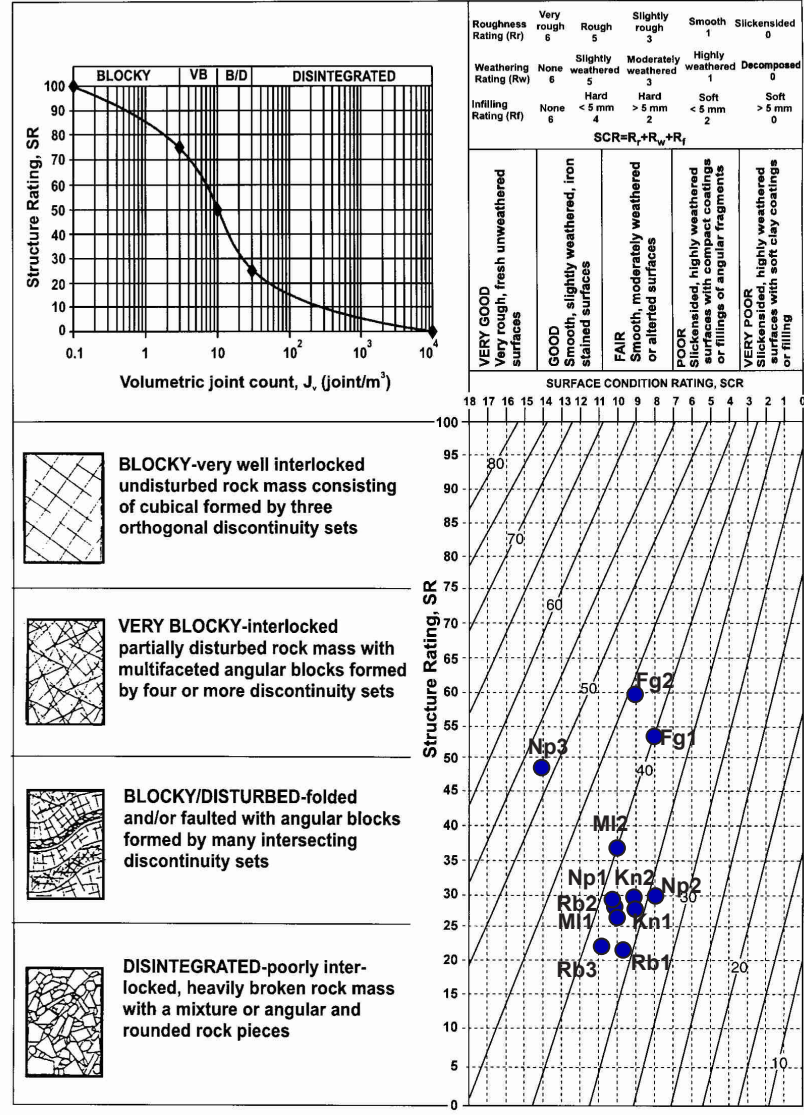

Fig. 8 A chart showing GSI value of Nawakot Complex. The chart is after Sonmez and Ulusay (1999) modified from Hoek (1994). respectively. Although all of the rock masses lie in same formation, $\mathrm{Rb} 1$ and $\mathrm{Rb} 3$ can be classified as disintegratedpoorly interlocked, heavily broken rock mass with a mixture or angular and rounded rock piece. $\mathrm{Rb} 2$ can be classified as blocky/disturbed-folded and/or faulted with angular blocks formed by many intersecting discontinuity sets because its SR is 28. But the rock masses of three of them have fair viz, smooth, moderately weathered or altered surface.

The GSI of the rock mass belonging to the formations of the Bhimphedi Group is shown in Fig. 10. In the location Rd1, the rock mass has GSI value $49 \pm 3$ because its $\mathrm{Jv}$ is 3.9 resulting the SR of 67 and has SCR of 10, but location $\mathrm{Rd} 2$ has GSI value $32 \pm 3$ because its $\mathrm{JV}$ is 16.56 resulting SR of 18 and SCR of 8 . Therefore, Rd1 can be classified as very blocky-interlocked partially disturbed rock mass with multifaceted angular blocks formed by four or more discontinuity and $\mathrm{Rd} 2$ can be classified as disintegrated-poorly interlocked, heavily broken rock mass with a mixture or angular and rounded rock piece .The rock masses of both of the locations have fair surfaces.

The rock mass of the location Bh1 has GSI value of $32 \pm 3$. It has Jv of 25.42, SR of 28, and SCR of 7. It can be classified as blocky/disturbed-folded and/or faulted

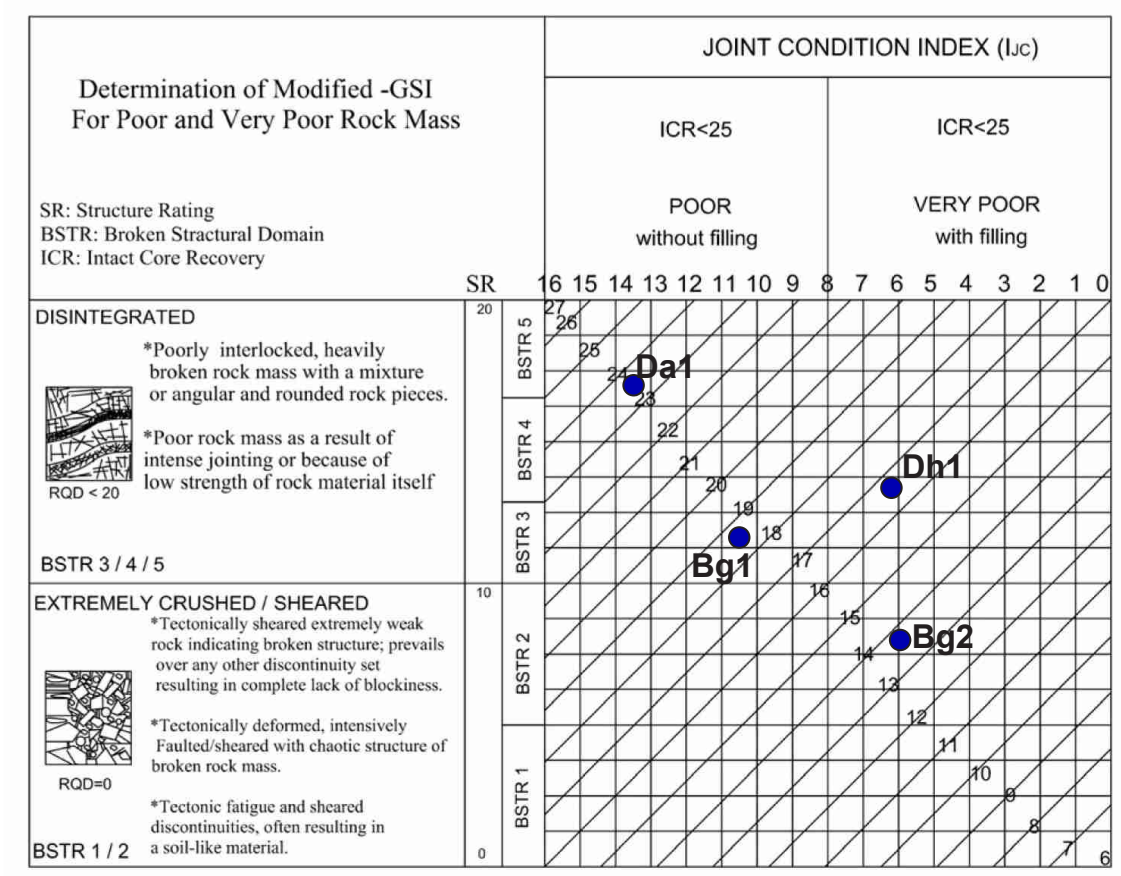

Fig. 9 Showing the GSI values of poor rock mass. The chart is after Osgoui et al. (2010). 
with angular blocks formed by many intersecting discontinuity sets and has surface intermediate between poor and fair.

Ka1 has Jv of 23.76 that results 30 SR, and has SCR of 9 resulting the GSI value of $37 \pm 3$ which is classified as blocky/disturbed-folded and/or faulted with angular blocks formed by many intersecting discontinuity sets and has fair surface.

The rock mass of location Ch1 has GSI value of $36 \pm 3$, because its Jv is 18.26 so that its SR is 18 and SCR is 10 . It is can be classified as disintegrated-poorly interlocked, heavily broken rock mass with a mixture or angular and rounded rock pieces and has fair surface.

Although the locations Kh1, Kh2, and Kh3 lie in same formation, the GSI value is different from each other. Kh1 has SR value of 18 and SCR of 13 so that its GSI value is $36 \pm 3$ and can be classified as disintegratedpoorly interlocked heavily broken rock mass with a mixture or angular and rounded rock pieces and has good surface condition. Kh2 has Jv of 1.07 that results SR of 83 and SCR of 11 so that its GSI value is $58 \pm 3$ and can be classified as blocky-very well interlocked undisturbed rock mass consisting of cubical formed by three orthogonal discontinuity sets. Kh3 has SR value 32 and SCR 9 so that its GSI value is $37 \pm 3$ and can be classified as blocky/disturbed-folded and/or faulted with angular blocks formed by many intersecting discontinuity sets and has fair surface.

Ti1 has SR of 33 and SCR of 10 so that the value of the rock mass of this location is $38 \pm 3$ and can be classified as blocky/disturbed-folded and/or faulted with angular blocks formed by many intersecting discontinuity sets and has fair surface.

Generally, different values of GSI are obtained (Table 2). Among all of them the highest GSI value is $58 \pm 3$ at $\mathrm{Kh} 2$ and the lowest value is at rock mass of $\mathrm{Bg} 2$ which is shown in Graph (Fig.11). Thus, the location Kh2 has Better quality of rock mass is categorized into very well interlocked undisturbed rock mass. $\mathrm{Bg} 2$ has lowest value due to its very poor rock mass. Location Da1, Dh1, Bg1 and $\mathrm{Bg} 2$ have very poor rock masses so it is classified on the basis of Osoui's criteria. Rest of locations belongs to disintegrated to blocky rock masses and categorized on the basis of Sonmez and Ulusay (1999) criterion. Here the location $\mathrm{Kn} 1, \mathrm{Rb} 1, \mathrm{Ka} 1$ and $\mathrm{Kh} 3$ has same GSI value

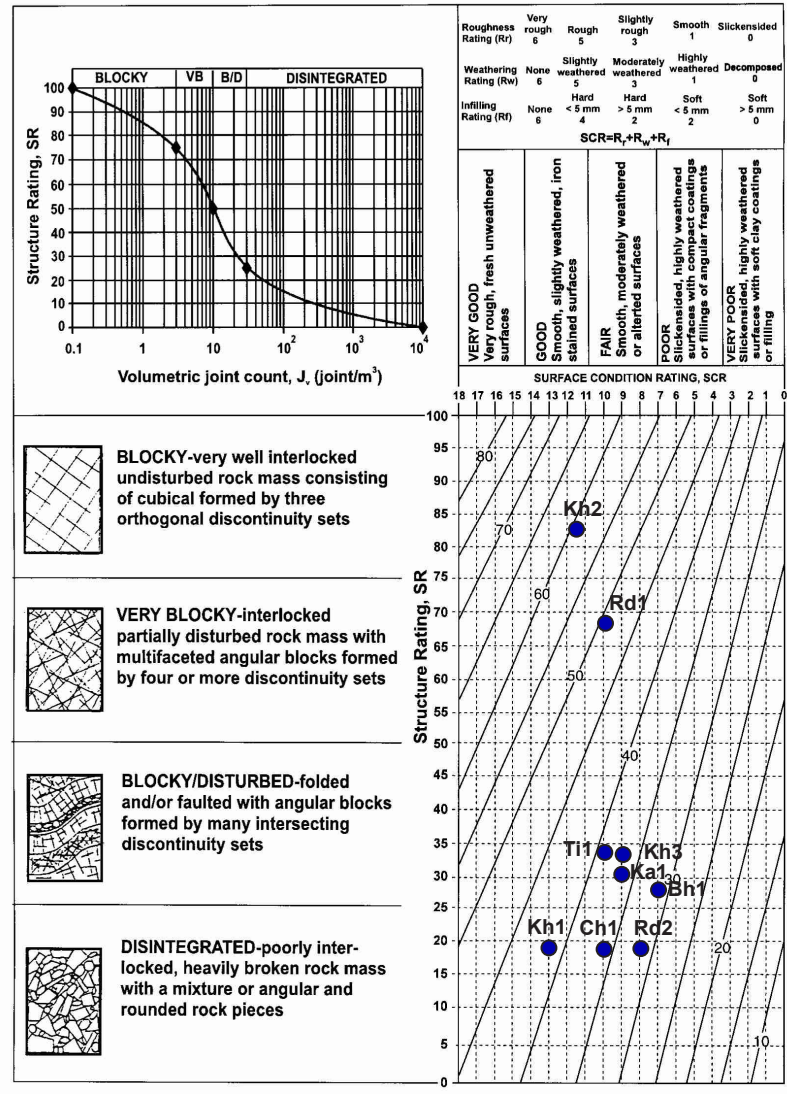

Fig. 10 A chart showing GSI value of Bhimphedi Group. The chart is after Sonmez and Ulusay (1999) modified from Hoek (1994).

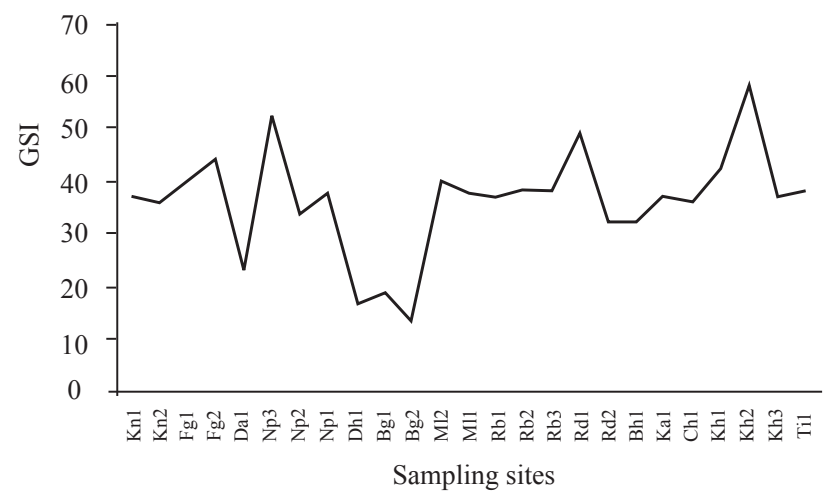

Fig. 11 Graphical representation of GSI in the study area.

of $37 \pm 3$. Among of these four locations Kn1, Ka1 and $\mathrm{Kh} 3$ can be categorized in block/disturbed rock masses but $\mathrm{Rb} 1$ lies in disintegrated rock mass because it has SR value of 22. Kh2 and Kh1 have also same GSI of $36 \pm 3$ but they lie in different categories. First one lies in blocky/disturbed rock mass because it has SR value of 30 but second one lies in disintegrated group because its SR value is less than 25. Both Fg1 and M12 have GSI of 
40. But previous one lies in very blocky rock masses because it has more than $50 \mathrm{SR}$ value whereas second one has only SR of 36 so it lies in blocky/disturbed rock masses. Although the location $\mathrm{Np} 1, \mathrm{Ml1}, \mathrm{Rb} 2, \mathrm{Rb} 3$, and Ti1 all have GSI value 38, and lies in disintegrated rock masses remaining are lies in blocky/disturbed rock masses.

\section{DISCUSSIONS}

In the original form of GSI system (Hoek and Brown, 1997), the rock mass is classified into 20 different categories with a letter code based upon the visual impression on the rock mass and surface characteristics of the discontinuities and GSI values ranging between 10 and 85 are estimated. Two additional rock mass categories, is called foliated/laminated rock mass structure and massive or intact rock, were introduced into the GSI system by Hoek et al. (1998) and Hoek (1999), respectively. Due to the anisotropic and heterogeneous nature of the foliated/laminated rock mass structure category, Marinos and Hoek (2001) also proposed a special GSI chart only for the classification of the heterogenous rock masses such as flysch. However, the classification scheme, in its existing form, leads to rough estimates of GSI values (Sonmez and Ulusay, 1999). Therefore, Sonmez and Ulusay (1999) made an attempt for the first time to provide a more quantitative numerical basis for evaluating GSI as a contributory use of the GSI system which is used in this studydue to the presence of disintegrated to blocky rock masses and also very poor rock masses.

RQD plays a main role in rock mass classification system. It is not suggested for poor and very poor rock masses due to difficulty in its estimation (in most cases value of RQD is zero). Osgoui et al. (2010) improved the GSI parameters to better classify poor and very poor rock masses and is based on both geological visual impression and quantitative measures and is also used in this study due to presence of poor rock masses.

The twenty five slopes have been studied along the Malekhu-Thopal River area and along the Dhading road. The RMR in the study area ranges from 36 to 82 , and GSI value from $16.6 \pm 3$ to $58 \pm 3$. Not only the rock masses are considered as poor due to such factors but also are affected by lithology. GSI and RMR have good and positive correlation (Fig. 12) suggesting that when RMR increases for the rock masses GSI also tends to increase. However, deviation from the trend is exhibited by weak rocks of slates (Benighat Slate), dolomite (Dhading Dolomite), phyllite (Dandagaon Phyllite) and schist (Kalitar Formation). Both of the RMR and GSI become high when lithology is competent (hard rock) and massive (thick), whereas less competent (soft rock) and thinly bedded rock have fewer values (Fig. 13). The Fagfog Quartzite and the Kulekhani Formation have medium to massive beds due to which their RQD values are higher than those of other formations and also the strengths of the intact rock are very high. In the study area mainly the Kunchha Formation and the Dandagaun Phyllite have less value because they comprise dominantly thin to medium foliated phyllite which has less strength and low resistance to weathering. Also in the case of slate it is thinly foliated and it breaks along its cleavage making a thin, platy layer due to which slate cannot be stable in their previous position when such joint cleavage is weathered. Due to this reason, the Benighat Slate has poor rock masses with less RQD and lesser GSI value.

The rock mass of the Dhading Dolomite is highly jointed and with very close spacing of discontinuity that resulted high Jv with less SR and RQD. Therefore, it is categorized into fair on the basis of RMR classification and disintegrated, heavily broken rock mass on the basis of GSI system.

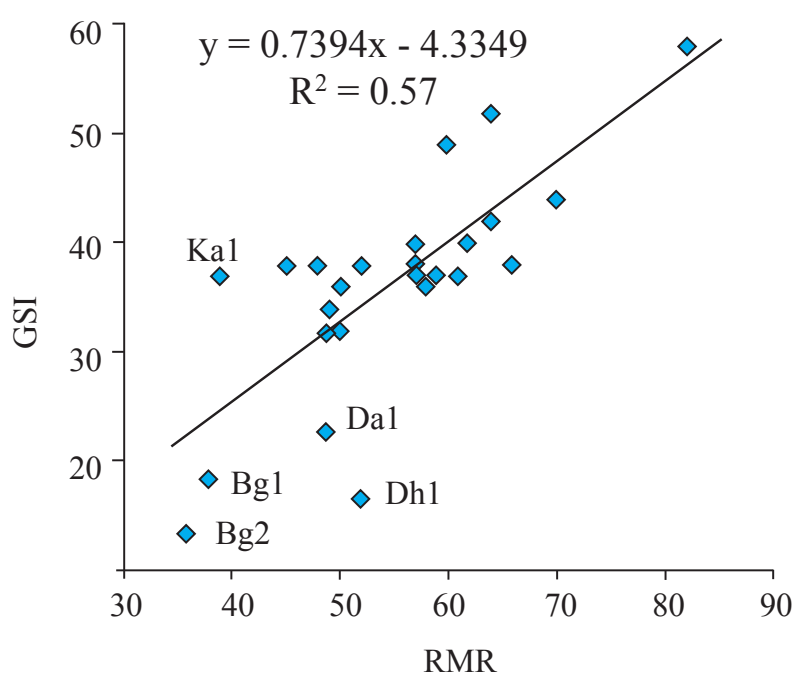

Fig. 12 Correlation between GSI and RMR of rock masses of the Thopal-Malekhu River area, Central Nepal Lesser Himalaya. 


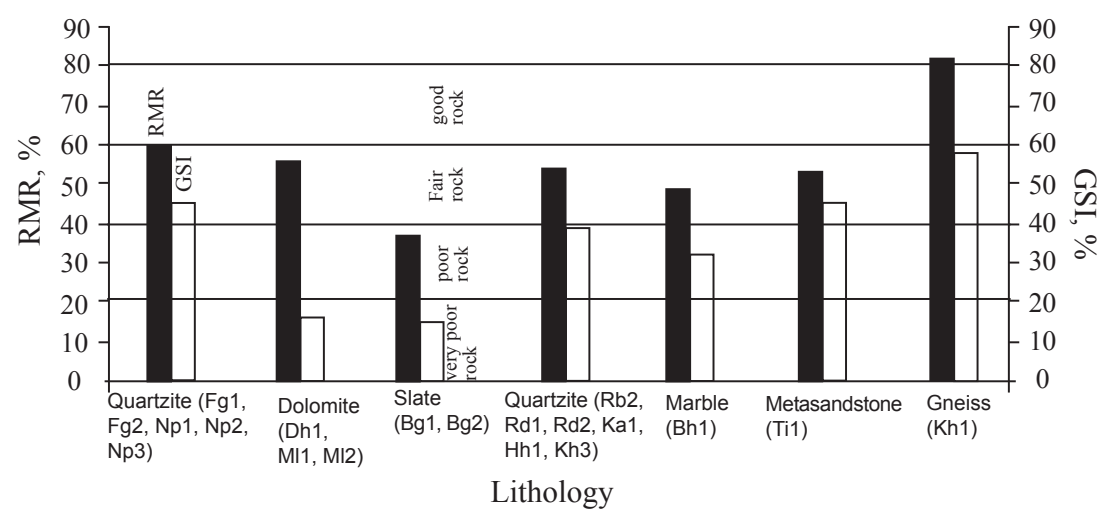

Fig. 13 Bar diagram showing RMR/GSI Vs lithology .

Ground water condition of rock masses also plays a vital role to make them poor. In the study area almost rock masses is in damp condition, but in the Benighat Slate and the Kalitar Formation there is wet to dripping condition of water that also has given the less RMR value leading them to poor rock mass categories.

In overall, rock masses of the Nourpul Formation, Dhading Dolomite, Malekhu Limestone, Raduwa Formation, Bhainsedobhan Marble, Chisapani Quartzite and the Tistung Formation are of fair rock mass categories, which have RMR ranging from 49 to 64 . The rock masses of the Kunchha Formation, the Dandagaun Phyllite and the Robang Formation are fair to good in which RMR ranges from 45 to 66 . The Khulekhani Formation has fair to very good rock masses ranging from 59 to 82, the Fagfog Quartzite has good rock mass and rest of the Formations: the Benighat Slate and the Kalitar Formation have poor rock masses. Same as the Kunchha Formation, the rock masses of the Nourpul Formation, Robang Formation, Bhainsedobhan Marble, Kalitar Formation and the Chisapani Quartzite have GSI values around $35 \pm 3$. The rock masses of the Fagfog Quartzite, Malekhu Limestone, Raduwa Formation, Kulekhani Formation, and the Tistung Formation have GSI around 40 to 55 . The rock masses of the Dhading Dolomite and the Benighat Slate have around $15 \pm 3$ and the Dandagaun Phyllite has $23 \pm 3$.

\section{CONCLUSIONS}

The following conclusions can be drawn from the present study:

1) RMR ranged from 36 (for the rock mass of slate) to 82 (for the rock mass of gneiss), being poor to very good, respectively, and the rest fall in fair to good rock mass categories. In terms of GSI, the majority of the rock masses have fair to good GSI ( $32 \pm 3$ to $58 \pm 3$ ), but only the highly fractured rocks of dolomite and thinly layered rocks like slates have GSI between $13.5 \pm 3$ and $23 \pm 3$, and fall in poor category.

2) The Benighat Slate is vulnerable as compare to other formations, because it has very poor rock masses that have less strength of intact rock, very poor quality of RQD, and close to very close spacing of discontinuity. Also there is probability of mass movement due to the dripping condition of water.

3) The rock masses of the Dhading dolomite and the Dandagaun Phyllite have disintegrated, poorly interlocked, and heavily broken rock masses due to which the GSI of the rock mass is very low. The rock masses of the Kulekhani Formation, Fagfog Quartzite, Nourpur Formation, and Tistung Formation have comparatively higher RMR and GSI so that their mechanical properties are also higher.

4) Considering the rock types, slate seemed to be poor rock with lower RMR and GSI, whereas quartzite, and metasandstone are fair to good rocks with moderate values of RMR and GSI, and gneiss is a very good rock in the study area.

5) Slates (of the Benighat Slate) are poor rock masses with low strength, very poor RQD, and close to very close spacing of discontinuity, and dolomites (Dhading Dolomite) are fair rocks with disintegrated, poorly interlocked, and heavily broken rock masses yielding very low RMR and GSI values. Phyllites (Dandagaun Phyllite), schist (Robang Formation) and quartzite (Fagfog Quartzite, Robang Formation and Chisapani Quartzite), dolomite (Malekhu Limestone), and metasandstone 
(Tistung Formation) are fair rock masses with moderate GSI and RMR values, whereas quartzose schist and gneiss (Kulekhani Formation) are very good rock masses having comparatively higher RMR and GSI.

6) GSI exhibits contrasting variation among the rock types compared to RMR. The relationship between GSI and RMR shows positive and good degree of correlation.

\section{ACKNOWLEDGEMENTS}

Authors are thankful to University Grant Commission (UGC) for financial support. Authors thank Prayag Maharjan and Krishna Kumar Bista for their assistance during field survey.

\section{REFERENCES}

Arita,K., 1983, Origin of the inverted metamorphismof the Lower Himalayas, Central Nepal. Techniphysics, v. 95, pp. 43-60.

Bhatta T. C.., 2006. Rock slope stability of right bank of dam area, middle Marsyangdi hydroelectric project Lumjung District, Central Nepal. M.sc. Thesis, Central Department of Geology, Tribhuvan University.

Bieniawski, Z.T., 1989. Engineering rock mass classifications. John Wiley and Sons.

Kumar, G., 1971. Geology and Sulfide Mineralization the Pokheri Area Chaoli District, Uttar Pradesh, Geological survey of India Miscelleneous Publication, Vol. 16, 1971, pp. 92-128.

Goodman, R. E., 1989. Introduction to rock mechanics (2nd edition). John Wiley, New York, 562p.

Hoek E., 1994. Strength of rock and rock masses. ISRM News J;2(2):4-16.

Hoek E., 1999. Puttingnumberstogeology-an engineer'sviewpoint.QJEngGeol., v. 32, pp.1-19. http://dx.doi.org/10.1144/GSL.QJEG.1999.032.P1.01

Hoek, E. and Brown, E.T. 1997. Practical estimates or rock mass strength. International Journal of Rock Mechanics and Mining Sciences, Vol. 34(8), pp. 1165-1186. http://dx.doi.org/10.1016/S1365-1609(97)80069-X

Hoek, E., Marinos, P. and Benissi, M., 1998. Applicability of the Geological Strength Index (GSI) Classification for very weak and sheared rock masses. The case of the Athens schist Formation. Bull. Engg. Geol. Env. 57(2), pp.151-160. http://dx.doi.org/10.1007/s100640050031

Marinos, P., Hoek, E., 2001. Estimating the geotechnical properties of heterogeneous rock masses such as Flysch. Bull. Eng. Geol. Environ. 60, 85-92. http://dx.doi.org/10.1007/s100640000090

Osgoui, R.R.,Ulusay, R. and Unal, E., 2010. An assistant tool for the Geological Strength Index to better characterize poor and very poor rock masses, International Journal of Rock Mechanics and Mining Sceince, Vol.47, pp.690-697. http://dx.doi.org/10.1016/j.ijrmms.2010.04.001

Palmstrom, A., 2005. Measurement of and Correlations between block size and Rock Quality Designation (RQD). Journal of tunneling and underground space Technology, Vol.20, pp.362-377.

Sakai, H., 1985, Geology of Kaligandaki Supergroup of the Lesser Himalayas in Nepal. Fac. Sci. Kyushu Univ., Japan. V. XXV, pp. 337-397.

Sharma, T. and Kizaki, K., 1989,Metamorphism and Thermal History of the Jaljala synclinorium, centraq west Nepal Himalaya. Jour. Nepal. Geol. Soc., v.6, pp. 21-34.

Shrestha M. B., Tamrakar, N.K., and Miyazaki, T., 2008. Morphometry and sediment dynamics of the Churiya River area, Siwalik Range in Neoal. Boletin de geologia, v. 30, no. 2, pp. 35-48.

Shrestha, P., and Tamrakar, N. K., 2007a, Streambank erodibility and lateral instability hjazard in the Manahara River, Kathmandu basin, Nepal. Jour. of Nepal Geol. Soc., v. 35, pp. 55-66.

Shrestha, P., and Tamrakar, N. K., 2007b, Bank erosion and bank material loss potential in Manahara River, Kathmandu, Nepal. Bull. Of Department of Geol., Tribhuvan University, Kathmandu, Nepal, v. 10,pp. 3344.

Sonmez, H. and Ulusay, R., 1999. Modification to the Geological Strength Index (GSI) and their Applicability to stability of Slopes, International Journal of Rock Mechanics and Mining Sceince, Vol.36, pp.743-760. http://dx.doi.org/10.1016/S0148-9062(99)00043-1

Stöcklin, J., 1981. Geology of Nepal and its regional Frame. Journal of the Geological Society of London, 137, pp. $1-34$.

http://dx.doi.org/10.1144/gsjgs.137.1.0001

Stöcklin, J., Bhattarai, K.D., 1977. Geology of the Kathmandu area and central Mahabharat range, Nepal Himalaya. Report of Department of Mines and Geology/ U N D P ( u n p u b lish e d ), $86 \mathrm{p}$. http://dx.doi.org/10.1144/gsjgs.137.1.0001

Tamrakar, N.K., Bajracharya, R. and Shrestha, P., 2011. River dynamics and existing stability condition of the Manahara River, Kathmandu basin, Central Nepal Himalaya. Bull. Dept. Geol., Tribhuvan University, v. 14, pp. -8. http://dx.doi.org/10.3126/bdg.v14i0.5430

Upreti, B. N. and Dhital, M. R., 1996. Landslide studies and management in Nepal. ICIMOD, $87 \mathrm{p}$.

Zekai Sen, and Bahaaeldin H. Sadagah, 2003. Modified rock mass classification system by continuous rating. eng. Geol., v. 67, pp. 269-280. 